\title{
Experimental Study on Coal Chars Oxy-Combustion in a Novel Furnace for Solid Fuels Characterization
}

\author{
Wojciech Adamczyk ${ }^{1}$, Ryszard Białecki ${ }^{1}$, Mario Ditaranto ${ }^{2}$, Nils Erland L. Haugen ${ }^{2}$, Anna Katelbach- \\ Woźniak $^{1}$, Adam Klimanek ${ }^{1}$, Sławomir Sładek ${ }^{1}$, Andrzej Szlęk ${ }^{1}$, Gabriel Węcel ${ }^{1}$ \\ ${ }^{1}$ Silesian University of Technology, Institute of Thermal Technology \\ Konarskiego 22, 44-100 Gliwice, Poland \\ wojciech.adamczyk@polsl.pl,ryszard.bialecki@polsl.pl,anna.katelbach-wozniak@polsl.pl, adam.klimanek@polsl.pl, \\ slawomir.sladek@polsl.pl, andrzej.szlek@polsl.pl,gabriel.wecel@polsl.pl
}

${ }^{2}$ SINTEF Energi A.S.

Sem Sælands vei 11, 7465 Trondheim, Norway

mario.ditaranto@sintef.no,nils.e.haugen@sintef.no

\section{Extended Abstract}

Oxy-combustion is considered as one of the main technologies for $\mathrm{CO}_{2}$ capture and storage. The oxy-combustion flue gas is almost a pure $\mathrm{CO} 2$ stream which can be transported to the sequestration site and stored. This technology is available for new boilers as well as for existing installations. Computational fluid dynamics (CFD) simulations are an important part of new boiler design process. Also for existing combustion chambers the CFD techniques can be used to predict impact of oxidizer change - from traditional air to oxygen. CFD analysis of combustion processes requires kinetic data of fuel conversion - devolatilization and char combustion/gasification. Obtaining these data is frequently costly and time consuming. It is important to obtain the experimental data at conditions similar to the simulated process conditions. Specifically the temperature, the heating rate, the thermal history, the pressure and the atmosphere are of importance [1]. Drop tube furnaces (DTF) are already standard devices used to retrieve such data. The conditions achievable in drop tube reactors are close or the same as in the real pulverized coal systems. Sometimes thermogravimetric analysis (TGA) is used to obtain kinetic data. This is however restricted to lower temperatures (below $1000{ }^{\circ} \mathrm{C}$ ), which results in the inability of observing the real diffusion restrictions at high temperatures. Therefore, TGA is frequently used in combination with the DTF to determine fuel characteristics at low and high temperature limits [2,3]. The investment and operating costs of the DTF are high and the measurement procedures are time consuming. This paper considers new method of char coal thermal conversion rate characterization.

The aim of this paper was to compare the combustion process of four different coal chars using FHC (Flat Horizontal Chamber). The main part of the device is a flat, horizontally oriented, electrically heated chamber supplied with a user selected mixture of gases flowing in a laminar regime. The solid fuel particles of diameter about $100 \mu \mathrm{m}$ can be fed from the top of the chamber to a fully developed laminar flow of gases. The particle trajectories are recorded by a high-speed camera through the quartz walls of the chamber. The walls are insulated and heated and the observation area is restricted to a rectangular aperture in the chamber wall. The measurements were conducted at two temperatures $1000{ }^{\circ} \mathrm{C}$ and $1100{ }^{\circ} \mathrm{C}$ and four different oxidizer compositions $\left(18,15,12,9 \% \mathrm{O}_{2}\right.$ in $\mathrm{O}_{2} / \mathrm{CO}_{2}$ mixture).

The particle trajectories are described by the particle equations of motion, in which the important terms are the gravity term as well as vertical and horizontal drag terms. While the drag depends on diameter, the gravity hinges on particle mass, thus the curvature of the trajectory is a function of particle diameter and mass. In case of inert gas flow the trajectories are linear since the horizontal velocity of the particle equalizes with gas flow velocity while vertical velocity stabilizes at the level for which force of gravity is equal to force of aerodynamic drag. In case of active gases $\left(\mathrm{O}_{2} / \mathrm{CO}_{2}\right.$ mixture $)$, analysisof trajectory curvature allows to determine the mean combustion rate of coal char particles.

The results showed the impact of process conditions on the rate of combustion of the fuel particles. Four different coal chares with different reactivity were compared. In the future work the obtained results will be used for CFD modelling of pulverized coal combustion process. 


\section{Acknowledgements}

The research leading to these results has received funding from the Polish-Norwegian Research Programme operated by the National Centre for Research and Development under the Norwegian Financial Mechanism 2009-2014 in the frame of Project Contract No Pol-Nor/232738/101/2014.

\section{References}

[1] E. Biagini and L. Tognotti, "A generalized correlation for coal devolatilization kinetics at high temperature," Fuel Processing Technology, vol. 126, pp. 513-520, 2014.

[2] S. Umemoto, S. Kajitani, and S. Hara, "Modeling of coal char gasification in coexistence of $\mathrm{CO} 2$ and $\mathrm{H} 2 \mathrm{O}$ considering sharing of active sites," Fuel, vol. 103, pp. 14-21, 2013.

[3] S. Kajitani, S. Hara, and H. Matsuda, "Gasification rate analysis of coal char with a pressurized drop tube furnace," Fuel, vol. 81, no. 5, pp. 539-546, 2002. 